\title{
PEMANFAATAN LIMBAH TERNAK SAPI BERBASIS “AGRIBUSSINES PRODUCT” DI DESA PERINA KECAMATAN JONGGAT KABUPATEN LOMBOK TENGAH
}

\author{
Muhammad Soadikin ${ }^{1}$, Novanita Laylatul Husna ${ }^{1}$, Amrulloh$^{2}$, Zihan Larasati², Desak Made Lucia \\ Damayanti $^{2}$, Ni Luh Sri Devi Yana ${ }^{2}$, Noor Laila Maharani ${ }^{3}$, Andre Aldy llyawan ${ }^{3}$, Abu Sa'it ${ }^{3}$, Siti Nur \\ Hazila $^{4}$, Abdurahim ${ }^{5}$, Ahmad Jupri ${ }^{12^{*}}$ \\ ${ }^{1}$ Fakultas Teknik, ${ }^{2}$ Fakultas Ekonomi, ${ }^{3}$ Fakultas Hukum, ${ }^{4}$ Fakultas Peternakan, ${ }^{5}$ Fakultas Teknologi Pangan \\ dan Agroindustri, ${ }^{12}$ Fakultas matematika dan IImu Pengetahuan Alam, Universitas Mataram Jl. Majapahit \\ No. 62 Mataram, NTB. \\ *Penulis korenspondensi: juprizikril@gmail.com
}

\begin{abstract}
ABSTRAK. Masyarakat di Desa Perine kebanyakan memelihara ternak sapi dan ikan, namun belum mengetahui cara mengolah limbah berupa kotoran atau fesses sapi untuk dijadikan sebagai pupuk organik padat (kompos). Padahal agar dapat memberikan manfaat yang maksimal, maka hasil sampingan pemeliharaan ternak sapi tersebut harus diproses sebelum dipergunakan sebagai pupuk. Umumnya proses pengolahan dimaksud terdiri dari dua kelompok, yakni pengolahan secara terbuka dan tertutup. Pada kegiatan ini telah dilakukan pengolahan feses sapi untuk digunakan sebagai pupuk organik untuk digunakan langsung oleh petani. Untuk itu, kegiatan ini diharapkan dapat meningkatkan kemandirian petani dalam memenuhi kebutuhan sendiri untuk berbagai keperluan dalam pertanian.
\end{abstract}

Kata kunci: pupuk, kompos, sapi, urea molases blok (UMB)

\begin{abstract}
Most people in Perine Village maintain cattle and fish, but do not know how to treat waste in the form of cow manure or fesses to be used as solid organic fertilizer (compost). Whereas in order to be able to provide maximum benefits, the by-products of cattle raising must be processed before being used as fertilizer. Generally the intended processing process consists of two groups, namely open and closed processing. In this activity, cow stool processing has been carried out to be used as organic fertilizer for direct use by farmers. For this reason, this activity is expected to increase the independence of farmers in meeting their own needs for various needs in agriculture.
\end{abstract}

Keywords: fertilizer, compost, cattle, urea molasses block (UMB)

\section{PENDAHULUAN}

Hasil sampingan pemeliharaan ternak sapi atau sering juga disebut sebagai kotoran sapi tersusun dari feses, urine dan sisa pakan yang diberikan (terutama untuk ternak yang dikandangkan). Hasil sampingan ini merupakan bahan utama pembuatan kompos yang sangat baik dan cukup berpotensi untuk dijadikan pupuk organik serta memiliki nilai hara yang cukup baik untuk kesuburan tanah (Budiyanto 2011).

\section{ANALISIS PERMASALAHAN}

Masyarakat di desa Perine kebanyakan memelihara ternak sapi dan ikan, di desa Perine masyarakat belum terlalu mengetahui bagaimana cara mengolah limbah kotoran atau fesses sapi untuk dijadikan sebagai pupuk organik padat (kompos). Agar dapat memberikan manfaat yang maksimal maka hasil sampingan pemeliharaan ternak sapi tersebut harus diproses sebelum dipergunakan sebagai pupuk. Umumnya proses pengolahan dimaksud terdiri dari dua kelompok, yakni pengolahan secara terbuka dan tertutup. 
Pengolahan secara terbuka dilakukan hanya dengan menumpukan kotoran ternak sapi pada suatu area tertentu selama waktu yang tidak tentu (Kementerian Pertanian. 2011). Namun pada umumnya dipergunakan menjelang musim tanam atau pada saat pengolahan tanah dilakukan. Cara ini tidak membutuhkan biaya yang terlalu banyak, karena biaya yang dikeluarkan hanya untuk tenaga kerja dan tidak diperhitungkan karena tenaga yang dipergunakan adalah tenaga keluarga.

Pengolahan yang kedua adalah dengan proses tertutup. Cara ini dilakukan dengan membenamkan kotoran ternak ke dalam sebuah lubang yang telah dipersiapkan sebelumnya. Pembuatan lubang/silo disarankan untuk dilakukan di bawah naungan dan areal yang tidak mudah tergenang air bila terjadi musim hujan. Di bawah naungan dapat diartikan sebagai tempat di bawah pohon yang rindang atau pun di bawah naungan atap yang memang disiapkan untuk tujuan tersebut (Hardoyo 2014).

\section{SOLUSI YANG DITAWARKAN}

Disini kami memilih menggunakan pembuatan kompos dengan cara proses terbuka, karena keterbatasan tempat atau lokasi yang digunakan untuk membuat kompos. Disini pengertian dari kompos tersebut adalah hasil penguraian parsial/tidak lengkap dari campuran bahan-bahan organik yang dapat dipercepat secara artifisial oleh populasi berbagai macam mikroba dalam kondisi lingkungan yang hangat, lembab, dan aerobik atau anaerobic. Sedangkan proses pengomposan adalah proses dimana bahan organik mengalami penguraian secara biologis, khususnya oleh mikroba-mikroba yang memanfaatkan bahan organik sebagai sumber energi. Membuat kompos adalah mengatur dan mengontrol proses alami tersebut agar kompos dapat terbentuk lebih cepat. Proses ini meliputi membuat campuran bahan yang seimbang, pemberian air yang cukup, pengaturan aerasi, dan penambahan aktivator pengomposan.

Adapun manfaat dari kompos tersebut adalah Kompos akan meningkatkan kesuburan tanah dan merangsang perakaran yang sehat. Kompos memperbaiki struktur tanah dengan meningkatkan kandungan bahan organik tanah dan akan meningkatkan kemampuan tanah untuk mempertahankan kandungan air tanah. Aktivitas mikroba tanah yang bermanfaat bagi tanaman akan meningkat dengan penambahan kompos. Aktivitas mikroba ini membantu tanaman untuk menyerap unsur hara dari tanah dan menghasilkan senyawa yang dapat merangsang pertumbuhan tanaman. Aktivitas mikroba tanah juga diketahui dapat membantu tanaman menghadapi serangan penyakit.Tanaman yang dipupuk dengan kompos juga cenderung lebih baik kualitasnya daripada tanaman yang dipupuk dengan pupuk kimia, misal: hasil panen lebih tahan disimpan, lebih berat, lebih segar, dan lebih enak (Hapsari 2013).

Kompos memiliki banyak manfaat yang ditinjau dari beberapa aspek :

Aspek Ekonomi :

1. Menghemat biaya untuk transportasi dan penimbunan limbah

2. Mengurangi volume/ukuran limbah

3. Memiliki nilai jual yang lebih tinggi dari pada bahan asalnya

Aspek Lingkungan :

1. Mengurangi polusi udara karena pembakaran limbah

2. Mengurangi kebutuhan lahan untuk penimbunan 
Aspek bagi tanah/tanaman :

1. Meningkatkan kesuburan tanah

2. Memperbaiki struktur dan karakteristik tanah

3. Meningkatkan kapasitas serap air tanah

4. Meningkatkan aktivitas mikroba tanah

5. Meningkatkan kualitas hasil panen (rasa, nilai gizi, dan jumlah panen)

6. Menyediakan hormon dan vitamin bagi tanaman

7. Menekan pertumbuhan/serangan penyakit tanaman

Jumlah perbandingan hasil kotoran beberapa jenis ternak dapat dijadikan bahan sebagai patokan dalam pembuatan pupuk organik yang berasal dari kotoran ternak itu sendiri. Dari data yang ada dapat dilihat bahwa sapi merupakan ternak dengan hasil kotoran terbanyak dalam sehari yaitu $23.59 \mathrm{~kg}$ (Harahap 2007). Data jumlah kotoran beberapa ternak dapat dilihat pada tabel dan grafik berikut.

Tabel 1.1 jumlah kotoran ternak padat

\begin{tabular}{cc}
\hline Jenis ternak & Kotoran padat (kg/hari) \\
\hline Sapi & 23,59 \\
Kuda & 16.1 \\
Kambing & 1.13 \\
Ayam & 0.05 \\
\hline
\end{tabular}

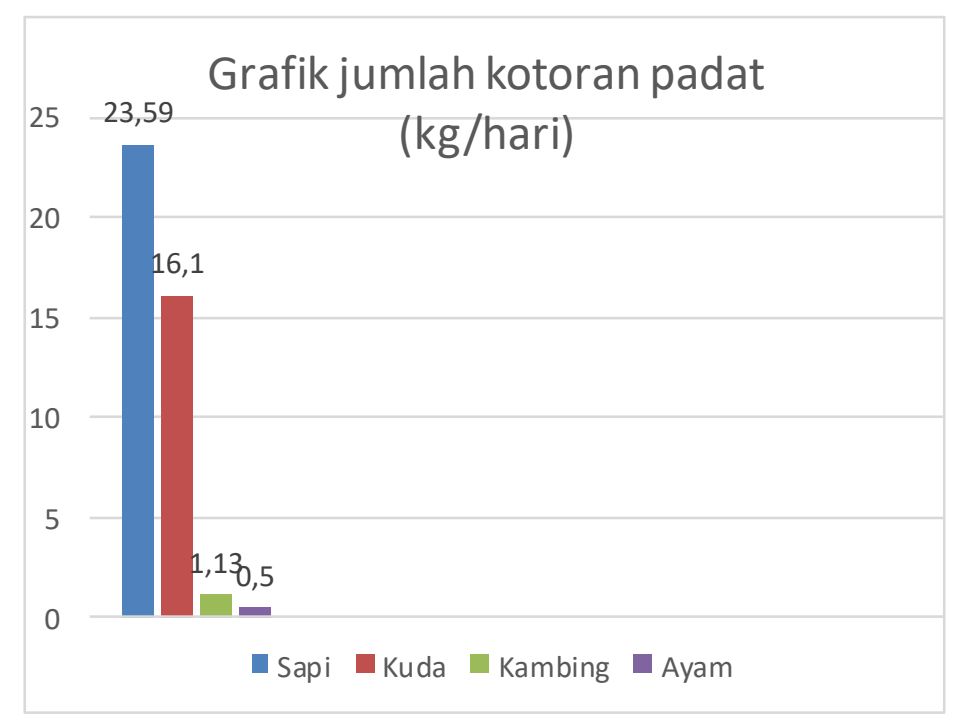

Gambar 1. Grafik jumlah kotoran ternak padat

\section{Metode Pelaksanaan}

\section{Waktu dan Tempat Pelaksanaan}

Waktu dilaksanakan kegiatan ini mulai pada hari minggu 5 Agustus 2018 sampai dengan hari sabtu 1 September 2018. Selama 1 bulan di Desa Perine Kecamatan Jonggat Kabupaten Lombok Tengah, di 3 dusun Perine yaitu Perine Daye, Perine Lauq dan Lendang Bonter. 


\section{Alat dan Bahan}

Alat yang digunakan dalam pembutan kompos ini adalah seperti sekop, terpal dan alat penyemprot. Sedangkan bahan yang digunakan sangat mudah didapatkan yaitu abu sekam, kotoran sapi, em4, molases, sisa pakan dan air secukupnya.

\section{Prosedur pembuatannya}

Cara pembuatan kompos ini sangat mudah dilakukan dan sederhana seperti berikut :

1. Membuat larutan stater em4, molases dan air dengan perbandingan 1:2:1 (1 tutup botol em4, 2 tutup botol molases dan 1liter air)

2. Membuat lapisan pada bahan kotoran ternak yang akan diolah sebagai pupuk organik lalu semprotkan bahan stater lagi bikin lapisan di atas setiap bikin lapisan semprotkan stater.

3. Ketika stater sudah habis di pakai, maka tumpukkan tersebut ditutup memakai terpal untuk proses decomposer setiap seminggu sekali harus di balik supaya mempercepat proses decomposer.

4. Setelah selesai proses decomposer maka pupuk organik siap di gunakan atau di pasarkan.

\section{HASIL DAN PEMBAHASAN \\ Pembuatan Pupuk Kompos}

Di dalam mengisi unsur hara dalam tanah, pupuk dapat digolongkan menjadi dua golongan (berdasarkan proses terjadinya), yaitu pupuk anorganik dan organik. Pupuk anorganik atau pupuk komersial yang saat ini dihasilkan oleh beberapa perusahaan pupuk nasional. Sedangkan pupuk organik dapat dibuat oleh petani langsung dengan menggunakan bahan-bahan organik yang tersedia di sekitar seperti kotoran ternak, limbah biomassa, dan lain-lain.

Kedua pupuk tersebut memiliki kelebihan dan kekurangan. Kelebihan yang dimiliki oleh pupuk anorganik (pupuk buatan pabrik) antara lain: 1) praktis dalam penggunaan, 2) tidak membutuhkan banyak waktu dan tenaga, dan 3) mudah diserap tanaman. Adapun kekurangan yang dimiliki oleh pupuk anorganik adalah: 1) merusak tektur dan struktur tanah dan 2) produk yang dihasilkan berbahaya bagi tubuh.

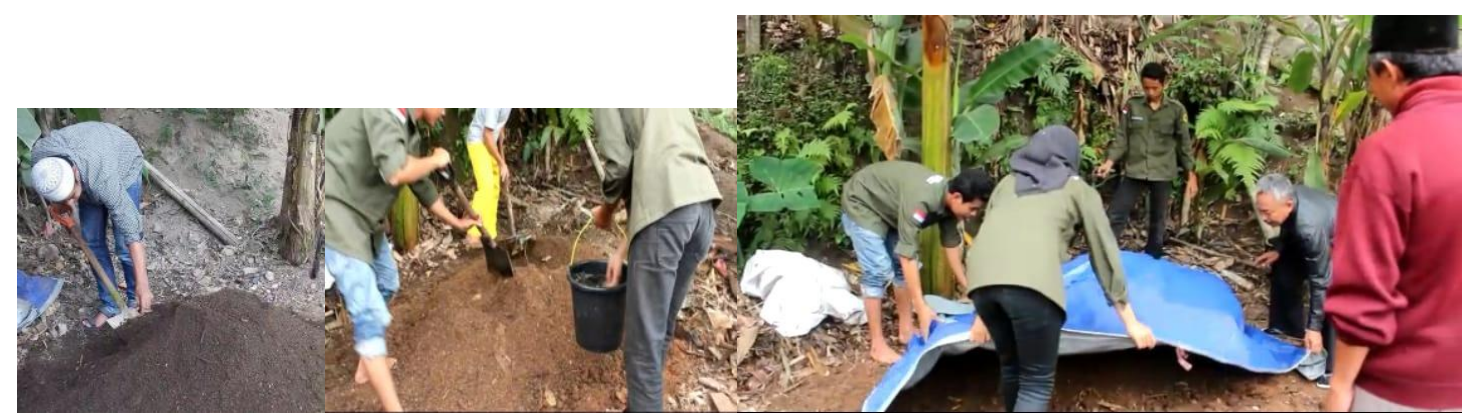

Gambar 2. Proses pembuatan pupuk

Pupuk organik atau yang sering dikenal dengan pupuk alami memliki beberapa kelebihan yaitu: 1) dapat dibuat sendiri, 2) terjangkau 3) dapat memperbaiki tekstur dan struktur tanah, 4) penyediaan unsur hara dan 5) tidak berbahaya bagi kesehatan manusia.Kegiatan pembuatan pupuk kompos dapat diterima dengan baik oleh masyarakat Desa Perina, dilihat dari antusias masyarakat yang telah ikut serta dalam pelatihan dan pelaksanaan pembuatan pupuk kompos. Masyarakat telah mulai memanfaatkan kotoran-kotoran ternak untuk membuat pupuk organik. 
Melalui kegiatan pembuatan pupuk organik in, masyarakat mulai terbiasa untuk mencegah penumpukan kotoran ternak di tempat mereka tinggal. Sehingga aneka penyakit yang muncul akibat penumpukan kotoran ternak tersebut dapat dikurangi. Selain itu, pemanfaatan kotoran ini dapat meningkatkan kebersihan lingkungan serta mengurangi pencemaran (polusi) baik udara (bau) maupun tanah dan air.

Hambatan yang masih terjadi adalah berpencarnya lokasi peternak melakukan budidaya sapi. Akibatnya, karena volume feses relatif sedikit maka peternak enggan untuk memanfaatkan feses yang masih sedikit tersebut. Untuk memecahkan masalah tersebut, maka adanya kelompok peternak dengan kandang kolektif akan sangat mendukung kegiatan ini. Selain itu, proses pelatihan tidak perlu dilakukan secara individu namun cukup mengikutsertakan pengurus kelompok ternak yang bersangkutan.

\section{KESIMPULAN}

Animo masyarakat untuk melakukan upaya pemanfaatan kotoran ternak menjadi pupuk organik sangat tinggi. Untuk itu, kegiatan ini harus dibiasakan sehingga menjadi kebutuhan masyarakat untuk memenuhi kebutuhannya terhadap pupuk organik. Namun karena pola pemeliharaan ternak yang dilakukan secara individu, maka peternak enggan untuk melakukan pengolahan sendiri-sendiri. Saran yang diajukan adalah mendorong pembentukan kelompok peternak dengan kandang kolektif sehingga pemanfaatan feses sebagai pupuk dapat dilakukan secara efektif.

\section{DAFTAR PUSTAKA}

Budiyanto, Krisno.2011. Tipologi Pemberdayaan Kotoran Sapi dalam Upaya Mendukung Pertanian Organik. Jurnal GAMMA 7 (1) $42-49$.

Melse, Roland dan Maikel Timmerman.2009. Sustainable Intensive Livestock Production Demands Manure and Exhaust Air Treatment Technologies.Jurnal Science Direct Bioresource Technology 100(2009) 5560-5536.

Rahayu, Sugi, Dyah Purwaningsih dan Pujianto. 2009. Pemanfaatan Kotoran Ternak Sapi Sebagai Sumber Energi Alternatif Ramah Lingkungan Beserta Aspek Sosio Kulturalnya. Jurnal notek Volume 13 No.2.

Sarwanto, Doso. 2004. Model Pencemaran Limbah Peternakan Terpadu dan Agribisnis yang Berwawasan Lingkungan. Seminar Nasional Teknologi Peternakan dan Veteriner. Universitas Padjajaran Bandung.

Hapsari, A.Y. 2013.Kualitas dan Kuantitas kandungan Pupuk Organik Limbah Serasah dengan Inokulan Kotoran Sapi Secara Semianaerob.Fakultas Perguruan dan Ilmu Pendidikan.Universitas Muhammadiyah Surakarta. Solo.

Harahap. V. I. 2007. Uji Beda Komposisi Campuran Kotoran Sapi Dengan Beberapa Jenis Limbah Pertanian Terhadap Biogas Yang Dihasilkan.Skripsi. Fakultas Pertanian. Universitas Sumatra Utara. Medan.

Hidayati Y. L, E. T. Marlina, E. Harlia. 2010. Pengaruh Imbangan Feses Sapi Potong dan Sampah Organik pada Proses Pengomposan Terhadap Kualitas Kompos.Universitas Jambi. Jambi.Jurnal Penelitian Universitas Jambi Seri Sains, Volume 12(3):54-57.

Murbandono, H. S.1998. Membuat Kompos.Penebar Swadaya. Jakarta.

Setiawan, A.I., 2005. Memanfaatkan Kotoran Ternak. Penebar Swadaya, Cetakan ke 10, Jakarta.

Bapedal. 1998. Buku Panduan Teknologi Pengendalian Dampak Lingkungan. Jakarta. 
Jurnal Warta Desa

www.jwd.unram.ac.id

Vol. 1 NO. 1 April 2019

Dahono. 2012. Pembuatan Kompos dan Pupuk Cair Prganik dari Kotoran dan Urin Sapi. Loka Pengkajian Teknologi Pertanian Kepulauan Riau.

Hardoyo, dkk. 2014. Panduan Praktis Membuat Biogas Portabel Skala Rumah Tangga dan Industri. Lily Publisher. Yogyakarta.

Kementerian Pertanian. 2011. Pedoman Teknis Unit Pengolah Pupuk Organik (UPPO) TA. 2011. Direktorat Jenderal Prasarana dan Sarana Pertanian. Jakarta. 